Introduction Gender bias in science is a global issue. Being an editor in a journal is considered to be representation of an individual's reputation and leadership. While gender disparity in editorial board of journals in several specialities, has been studied, but not in Occupational Safety and Health (OSH).

Methods MEDLINE indexed journals were searched in the NLM, USA Catalogue with a search strategy. The list of journals retrieved were reviewed to access whether they were in the domain of OSH.

Information pertaining to editors and their roles was obtained from journal websites in June 2017. At this phase, journals which had no editorial list or did not have full names of editors in their websites were excluded. Any individual whose role which was not designated as editor was excluded from the analyses. Gender was determined by multiple methodologies: inspection of names, gender- specific description, photographs in journal or institutional web pages. All data was validated independently by the two authors and differences sorted by consensus.

Since the study used data available in public domain and no human participants were involved it did not require ethics committee approval.

Results 22 journals were retrieved from the NLM catalogue and 16 of them were finally included with a total of 185 editors. Gender could not be determined by for 11 (5.94\%) editors and there were 56 female (30.27\%) editors and 118 male $(63.78 \%)$ editors. 3 out of $16(18.75 \%)$ Editor-in-Chief, 2 out of $8(25 \%)$ Managing editors and 39 out of 101 (38.61\%) Associate editors were female.

Discussion This is the first study providing data on gender diversity in editorial boards of OSH journals and shows significant gender inequity. Qualitative research to understand the enablers and barriers for women to become editors in $\mathrm{OSH}$ journals is warranted.

\section{INEQUITIES OF WORKING WOMEN IN THE INFORMAL SECTOR: A GLOBAL PERSPECTIVE}

${ }^{1}$ Igor Bello*, ${ }^{2}$ Marcia Bandini*. ${ }^{~}$ Dr. University of Carabobo, Valencia, Venezuela; ${ }^{2}$ President of the Brazilian Association of Occupational Medicine ANAMT, Sao Paulo, Brazil

\subsection{6/oemed-2018-ICOHabstracts.1507}

The aim of this special session Women are majority in the informal work and informal employment, facing socioeconomic inequalities that will be shown during this session.

${ }^{1} \mathrm{~J}$ Rodriguez-Guzman, ${ }^{2} \mathrm{SM}$ Copsey, ${ }^{3} \mathrm{O}$ Solar

${ }^{1}$ Prof. Dr. Regional Advisor on Worker's Health, Pan-American Health Organisation/World Health Organisation PAHO/ WHO, Washington, USA

${ }^{2}$ Ms. European Agency for Safety and Health at Work (EUOSHA), Bilbao, Portugal

${ }^{3}$ Dr. International Labour Office, Geneva, Switzerland

\section{0a PAHO'S REGIONAL EFFORTS TO OVERCOME GENDER INEQUALITIES FOR WORKING WOMEN IN THE AMERICAS}

J Rodriguez Guzman. Regional Advisor on Workers' Health, Dept. Family, Direction of Gender and Life Course FGL, Pan-American Health Organisation
PAHO is committed to promote gender equality in health status and health development through research, policies, and programs which give due attention to gender differences in health and its determinants. To achieve this PAHO's Gender Equality Policy is implemented as a cross-cutting policy. All directions and programs of PAHO implement actions in their respective field of expertise, and actively promote equality between women and men. This policy reflects PAHO's unwavering commitment to the principles of equity, respect for human rights, and the exercise of citizenship, in addition to its determination to actively participate in global efforts to eliminate all forms of gender discrimination. The ultimate goal is to achieve gender equality. PAHO has created Gender Observatories since 2009, as channels for monitoring and tracking public policy, anticipating emerging social developments, and gaining empirical evidence, based on official data, regarding the Status of women, and their inequalities in relation to men.

Despite all the efforts, the balance remains to be unequal because of the conditions under which women join the formal and informal sectors. These determine their opportunities to benefit from social protection in health schemes, access and out-of-pocket expenditures. Although several types of schemes were developed during the last two decades to reform social protection systems, they still have significant differences in access for women and men. Women generally are excluded from social security because most of them are in low-productivity informal sectors, limiting their autonomy and empowerment.

1. Women have fewer opportunities to access contributory health protection systems caused by the limitations of the labour market (segregation, no contracts, salary gaps, lack of social benefits);

2. The unpaid workload of caregivers as a major factor limiting job opportunities (increasing due to NCDs and ageing population);

3. Women's working conditions limit their access to pension and retirement plans with health coverage (Women access much less pension and retirement benefits); and,

4. Women pay more out-of-pocket expenses (higher due to service demand and car for family).

In 2017 World Woman's day, PAHO called for action to overcome barriers to accessing social protection in health in the reforms of social protection systems. Social health protection policies must be based on the right to health, addressing and responding to the specific needs of women's different situations. The following recommendations included: avoiding to linking access to social protection in health schemes to formal employment or contributory schemes; increase and improve health insurance coverage, with equity, efficiency, and sustainability, promoting the elimination of direct payment at the point of access to health services, as well as eliminating additional payments by women due to their reproductive role; offer comprehensive health services for women in basic services schemes (in addition to sexual and reproductive health care); and, develop social policies that address the issue of unpaid care in the home, without perpetuating the role of women as caregivers. It is necessary to seek a fair distribution of labour among the state, the community, the private sector, and households - and within households, between men and women. 